\title{
Influence of Fetal Extracellular Volume Contraction on Renal Reabsorption of Bicarbonate in Fetal Lambs
}

\author{
JEAN E. ROBILLARD, (5.4) CHRISTINE SESSIONS, LEOON BURMIEISTER, AND FRED G. SMITH, JR. \\ Department of Pediatrics and Preventive Medicine, University of Iow'a, Lowa City, and from the Department of \\ Pediatrics, University of Montreal, and Centre de Recherche' P'édiatrique, Hopital Ste-Justine', Montreal. Quebec,
} Canala

\begin{abstract}
Summary
In order to determine the renal threshold for bicarbonate in the fetal lamb and factors that may influence renal reabsorption of bicarbonate in the fetus, 18 acute fetal lamb preparations (110-140 days of gestation) were studied. In the first series of experiments involving nine fetuses, the renal bicarbonate threshold of normal fetuses varied from 12.0 to $23.5 \mathrm{mM} / \mathrm{liter}$ with a mean value of $17.7 \pm 1.37 \mathrm{mM} /$ liter. This is significantly lower $(P<0.005)$ than the value measured in five adult sheep of 28.7 $\pm 1.68 \mathrm{mM}$ /liter. There was a significant and positive correlation between the fetal plasma bicarbonate at threshold level and the fetal kidney weight, as well as fetal age. In a second series of experiments, the excretion of bicarbonate and sodium was studied in nine fetuses before and after dehydration by peritoneal dialysis. After peritoneal dialysis there was a significant decrease in urinary pH $(P<0.025)$, bicarbonate excretion $(P<0.001)$, sodium excretion $(P<0.001)$, fractional excretion of sodium $(P<0.001)$, and a significant increase in bicarbonate reabsorption $(P<0.01)$. When glucose was replaced by mannitol in the peritoneal dialysis fluid the effects on bicarbonate reabsorption paralleled those when glucose was present in dialysis fuid. It was also shown that when glucose was given intravenously to the fetus, up to a plasma concentration of $200 \mathrm{mg} / 100 \mathrm{ml}$, there was no effect on the fetal renal reabsorption of bicarbonate. These data indicate that the low threshold for bicarbonate reabsorption by the fetal kidney is not due to a limited capacity to increase bicarbonate or sodium reabsorption and suggest that the fetal kidney is able to respond to volume depletion by increasing its reabsorption in bicarbonate and electrolytes.
\end{abstract}

\section{Speculation}

A number of factors have been suggested to explain the low bicarbonate threshold observed during fetal life and during the early newborn period. These include the immaturity of the nephron, the oncotic pressure in the peritubular capillary circulation, the influence of distribution of intrarenal blood flow, the role played by the renin-angiotensin aldosterone system, and the effect of $\alpha$ and $\beta$ adrenergic stimulation.

The present study suggests that the state of high extracellular fluid volume that exists during fetal life and the early newborn period significantly infuences the maturation of the renal threshold for bicarbonate.

The regulation of acid-base homeostasis by the mature kidney involves the reabsorption of filtered bicarbonate on the one hand and the excretion of hydrogen ion as titrable acid and ammonium on the other.

The ability of the fetal kidney to excrete fixed acids and to establish an adult-type gradient of $\mathrm{pH}$ between blood and urine has been previously investigated $(30,41)$. Vaughn and associates (41) have shown that the excretion of titrable acid and ammonium per unit of body weight was considerably less in the fetal lamb than in adult animals. Smith (30) demonstrated that even when renal compensation to metabolic acidosis in the fetus is limited as compared with that of the adult, the fetal lamb kidney is able to increase hydrogen ion excretion significantly in response to prolonged and profound metabolic acidosis in a manner qualitatively similar to the adult animal. Recently, Moore (18), demonstrating a clearcut pH gradient between blood and urine in fetal lambs after infusion of $\mathrm{Na}_{2} \mathrm{SO}_{4}$, suggested that a possible lack of avidity for renal reabsorption of $\mathrm{Na}^{+}$in exchange of $\mathrm{H}^{+}$might explain the defect of urinary acidification in the fetus. However, these studies still do not exclude a functional tubular immaturity in the transport of bicarbonate to explain the low capacity of the fetus for urinary acidification.

It is well known that the physiologic acidosis seen in newborn animals is due to a low renal plasma bicarbonate threshold $(7$, 19). This decreased threshold for bicarbonate can be markedly increased in newborn puppies under the stimulus of extracellular volume contraction (19). However, the results found in newborn animals may not necessarily be extrapolated to the fetus where the integrity of acid-base balance depends much on the proper functioning of the placenta and where the fetal-maternal-amniotic fluid complex constitutes a three-compartment system in close relationship.

The present study was designed: (1) to investigate the capacity of the fetal lamb kidney to reabsorb bicarbonate and (2) to use this model for the exploration of factors that might influence the fetal threshold for bicarbonate excretion.

\section{METHODS}

Studies of renal bicarbonate transport were carried out on a total of 18 fetal lambs, divided in two groups. Control values were determined from five adult nonpregnant sheep. The fetuses were weighed at the end of the experiment and their age determined as previously described $(12,24)$. The adult ewes were weighed before the experiment.

The threshold for bicarbonate excretion in the first group of nine fetuses (120-147 days of gestation) was compared to bicarbonate threshold in five adult sheep.

The fetuses were prepared using an acute intrauterine fetal preparation. In the ewes, spinal anesthesia was induced with 4 $\mathrm{ml}$ of a $2 \%$ lidocaine hydrochloride (43) solution, repeated when required during the experiment. The uterus was exposed and incised, and the hind leg of the fetus was delivered. Polyethylene catheters were placed into a pedal vein and artery, and advanced approximately $10-15 \mathrm{~cm}$ after local anesthesia was induced with lidocaine hydrochloride. Through the same uterine 
incision, the umbilical cord was located and exposed. The urachus was identified and ligated distally and a 3.5 French infant feeding tube was advanced $4-6 \mathrm{~cm}$ into the fetal bladder. The sight of urine flowing in the catheter was utilized to ensure proper placement of this catheter. The hind limb was replaced in the uterine cavity, and the fetal membrane, uterine cavity, and abdominal wall were closed.

After completion of the surgical procedures, control collections were obtained to measure glomerular filtration rate, bicarbonate reabsorption, and electrolyte $(\mathrm{Na}, \mathrm{K}, \mathrm{Cl})$ excretion. Thereafter, the fetal plasma bicarbonate concentration was lowered well below the renal threshold by intravenous infusion of $1.5 \mathrm{M}$ hydrochloric acid ( $\mathrm{HCl}$ ) in $5 \%$ dextrose and water at a rate of $0.1 \mathrm{ml} / \mathrm{min}$, corresponding to $0.02-0.05 \mathrm{ml} / \mathrm{min} / \mathrm{kg}$ of fetal body weight. After additional collection periods the infusion of $\mathrm{HCl}$ was stopped and a solution of $10 \%$ sodium bicarbonate containing $40 \mathrm{mEg} /$ liter of potassium was infused at the same rate $(0.1 \mathrm{ml} / \mathrm{min})$ and serial collections of urine at 15 -min intervals were made until the renal threshold for bicarbonate was passed. Renal bicarbonate threshold was defined arbitrarily as the level of bicarbonate in plasma at which the bicarbonate excretion in urine is $20 \mu \mathrm{Eq} / 100) \mathrm{ml}$ of glomerular filtration rate (GFR) $(7,38)$.

Control adult values for bicarbonate threshold were also determined in five adult sheep. After determination of control values for blood gases and electrolytes $\left(\mathrm{Na}^{+}, \mathrm{K}^{+}, \mathrm{Cl}^{-}\right)$, ammonium chloride was added to their morning feeding for 3 days to lower the concentration of plasma bicarbonate below the renal threshold. On the day of the experiment, the animal was immobilized with curare after insertion of an endotracheal tube. Respiration was regulated with a Harvard respiratory pump (4.4) adjusted to maintain the arterial pCO $\mathrm{CO}_{2}$ tension at approximately $34 \mathrm{~mm} \mathrm{Hg}$. The normal $\mathrm{pCO}_{2}$ in adult sheep has previously been shown to range between 30 and $34 \mathrm{~mm} \mathrm{Hg}(5,13)$. Control collections were then completed to determine glomerular filtration rate, bicarbonate reabsorption, and electrolyte $(\mathrm{Na}, \mathrm{K}, \mathrm{Cl})$ excretion. Thereafter, a solution of $10 \%$ hypertonic sodium bicarbonate containing $40 \mathrm{mEq} /$ liter of potassium was infused at $1 \mathrm{ml} / \mathrm{min}(0.02-0.04 \mathrm{ml} / \mathrm{min} / \mathrm{kg}$ of body weight) and serial collections of urine at 1.5 -min intervals were made until the renal bicarbonate threshold was passed. Potassium was added to the bicarbonate solution to maintain the plasma potassium concentration as close as possible to normal control values.

In the second group of nine fetuses (114-142 days of gestation), using an acute exteriorized fetal preparation, reabsorption and excretion of bicarbonate were studied before and after peritoneal dialysis used to produce a state of extracellular volume contraction. The fetuses were completely exteriorized as previously described (30) and kept at $39^{\circ}$ on a warm table adjacent to and level with the uterus. After three 15 -min control collection periods during which glomerular filtration rate, reabsorption of bicarbonate, and excretion of electrolytes ( $\mathrm{Na}, \mathrm{K}$, $\mathrm{Cl}$ ) were monitored, $50 \mathrm{ml} / \mathrm{kg}$ fetal body weight of a solution of Diancal $4.25 \%(45)$ containing $4 \mathrm{mEg} /$ liter of potassium and previously warmed at $39^{\circ}$ was placed in the fetal peritoneal cavity. After allowing 15 min for equilibration, three experimental periods of 15 min each were performed to evaluate the same parameters as those of the control periods. At the end of the last experimental period, the dialysis fluid was removed from the peritoneal cavity and compared to the predialysis solution of Dianeal for osmolarity, sodium, potassium, and chloride concentration.

Additional studies were carried out to determine whether the glucose present in the solution of Dianeal $4.25 \%$ could modify the renal bicarbonate reabsorption. Using the same acute exteriorized fetal preparation, three experiments were completed in which the solution of Diancal was replaced by a solution of mannitol $4.25 \%$ containing the same electrolyte mixture as Dianeal to which we added $4 \mathrm{mEq} /$ liter of potassium. Also, in order to monitor possible changes in fetal renal bicarbonate reabsorption when fetal plasma glucose increased, two chronic fetal lambs were studied using the preparation described by Gresham (12).

In both fetuses and nonpregnant adult sheep, GFR was determined as described previously (2t) using a constant infusion of sodium [125] ]iothalamate (46) (approximately $0.1 \mu \mathrm{Ci} / \mathrm{min} / \mathrm{kg}$ ). Arterial blood samples were collected anaerobically in heparinized glass syringes via an arterial catheter at the midpoint of each urine collection and analyzed immediately for $\mathrm{pH}$ and $\mathrm{pCO}_{2}$. Urine was also collected anacrobically in a glass syringe, kept on ice, and analyzed immediately after collection for total $\mathrm{CO}_{2}$ content and pll.

Blood and urine $\mathrm{pH}$ and blood $\mathrm{pCO}_{2}$ were measured at normal body temperature of $39^{\circ}$ with a Radiometer PlIM72 MK2 acid base analyzer $(47)$ with appropriate $\mathrm{pH}$ and $\mathrm{pCO}_{2}$ electrodes. Urine total $\mathrm{CO}_{2}$ was determined by the method of Van Slyke and Neill (40) using a Natelson microgasometer. Urine bicarbonate concentration was calculated from the Henderson-Hasselbach equation. The values for $\mathrm{pK}$ were calculated for each urine sample according to the formulat $\mathrm{pK}^{\prime}=6.33-(0.5 \sqrt{\mathrm{B}}$, where $\mathrm{B}$ represents the total cation concentration, estimated as the sum of sodium plus potassium expressed in equivalents per liter (14). The solubility coefficient used for $\mathrm{CO}_{2}$ in urine was 0.0309 . Blood bicarbonate was determined from $\mathrm{pH}$ and $\mathrm{pCO}_{2}$ values using the Siggaard Andersen nomogram (29).

The concentration of sodium and potassium in blood and urine were measured with a flame photometer $(48)$. Chloride in blood and urine was measured with a chloridometer (49). Blood and urine osmolarity were determined with an osmometer $(50)$. Concentration of total protein was determined by the biuret reaction and concentration of albumin was calculated from the pereentage of total protein accounted for by albumin as determined by electrophoresis on cellulose acetate $(8)$. Glucose in blood was measured by the glucose-oxidase method (27). Sodium [ ${ }^{125}$ I] lothalamate was counted in blood and urine on a Beckman Gamma 300 radiation counter (51).

Data were evaluated using the $t$-test for paired data to compare control to experimental values in the same group of animals, and for unpaired data for comparisons between groups. The regression curves were derived by the method of least squares.

\section{RIESULTS}

\section{DIETIRMINATION OF RINAL THRIESHOLD FOR BICARBONATE} IEXCRETION IN FETAL SHEEP

Control arterial blood values and urine $\mathrm{pH}$ from nine fetal lambs prior to the infusion of hydrochloric acid and bicarbonate titration are presented in Table 1.

In the adult nonpregnant ewes, mean arterial blood values for $\mathrm{pH}, \mathrm{pCO}_{2}$, bicarbonate, and electrolytes, determined be fore and after induction of metabolic acidosis, are presented in Table 2. The postacidification values were determined when the animals were on a respirator so as to maintain their pCO.2 values as close as possible to normal control values.

Values for plasma bicarbonate observed at threshold in fetal lambs and adult sheep are summarized in Table 3. Mean values for plasma bicarbonate at a threshold of $17.7 \mathrm{mmol} / \mathrm{liter}$ in fetal lambs is significantly lower than the mean value of $28.7 \mathrm{mmol} /$ liter found in adult sheep $(P<0.001)$, despite the fact that mean fetal $\mathrm{pCO}_{2}$ of 4.3 .9 at threshold is significantly higher than mean adult $\mathrm{pCO}_{2}$ of $32.8 \mathrm{~mm} \mathrm{Hg}(P<0.01)$. Arterial blood pH at threshold in the fetuses is also significantly lower than adult arterial pH $(P<0.001)$.

Plasma bicarbonate at threshold shows a significant correlation $(r=0.76)$ and a statistically significant positive regression $(P<0.01)$ when related to fetal kidney weight (Fig. 1). There is also a significant correlation $(r=0.6(1)$ and a significant positive regression $(P<0.05)$ when plasma bicarbonate at threshold is presented as a function of fetal age. However, a multiple regres- 
Table 1. Control acid-base status in nine fetal lambs

\begin{tabular}{|c|c|c|c|c|c|c|c|c|c|c|}
\hline \multirow[b]{3}{*}{ Fetus } & \multirow{3}{*}{$\begin{array}{l}\text { Age, } \\
\text { days }\end{array}$} & \multirow{3}{*}{$\begin{array}{c}\text { Weight, } \\
\mathrm{kg}\end{array}$} & \multicolumn{6}{|c|}{ Blood } & \multicolumn{2}{|c|}{ Urine } \\
\hline & & & \multirow[b]{2}{*}{$\mathrm{pH}$} & \multirow{2}{*}{$\begin{array}{l}\mathrm{pCO}_{2}, \\
\mathrm{~mm} \mathrm{Hg}\end{array}$} & \multirow{2}{*}{$\begin{array}{l}\mathrm{HCO}_{3}{ }^{-} \\
\mathrm{mmol} / \mathrm{liter}\end{array}$} & \multicolumn{3}{|c|}{$\mathrm{mEq} /$ liter } & \multirow[b]{2}{*}{$\mathrm{pH}$} & \multirow[b]{2}{*}{$\% \mathrm{FE}_{\mathrm{HWO}}{ }^{1}$} \\
\hline & & & & & & $\mathrm{Na}^{+}$ & $\mathrm{K}^{+}$ & $\mathrm{Cl}^{-}$ & & \\
\hline 71 & 136 & 3.15 & 7.29 & 50.0 & 23.6 & 150 & 4.6 & & 6.83 & 2.1 \\
\hline 73 & 130 & 2.60 & 7.41 & 47.0 & 29.3 & 136 & 3.3 & & 7.10 & 30.0 \\
\hline 74 & 134 & 3.00 & 7.21 & 52.0 & 20.0 & 146 & 4.5 & & 7.26 & 36.3 \\
\hline 76 & 136 & 3.15 & 7.36 & 51.0 & 28.4 & 134 & 3.4 & & 7.59 & 17.5 \\
\hline 80 & 120 & 1.80 & 7.38 & 39.5 & 23.0 & 132 & 4.9 & 104 & 6.50 & 1.0 \\
\hline 82 & 144 & 4.30 & 7.35 & 39.3 & 21.3 & 132 & 5.6 & 101 & 5.70 & 0.08 \\
\hline 83 & 147 & 4.70 & 7.37 & 43.1 & 24.5 & 1.33 & 4.3 & 104 & 6.88 & 1.5 \\
\hline 84 & 139 & 3.60 & 7.37 & 40.0 & 22.7 & 133 & 4.6 & 106 & 6.88 & 3.0 \\
\hline 85 & 145 & 4.41 & 7.42 & 38.1 & 24.8 & 137 & 4.4 & 98 & 7.20 & 26.9 \\
\hline Mean & & & 7.35 & 44.4 & 24.17 & 137 & 4.4 & 102.6 & & \\
\hline SE & & & 0.02 & 1.86 & 1.01 & 2.17 & 0.23 & 1.39 & & \\
\hline
\end{tabular}

${ }^{1}$ Percentage of filtered bicarbonate excreted.

Table 2. Acid-base status before and after induction of metabolic acidosis in five nonpregnant ewes

\begin{tabular}{|c|c|c|c|c|c|c|c|}
\hline \multirow{3}{*}{$\begin{array}{c}\text { Nonpregnant ewes } \\
(n=5)\end{array}$} & \multirow[b]{3}{*}{$\mathrm{pH}$} & \multicolumn{5}{|c|}{ Blood } & \multirow[b]{3}{*}{ Urine $\mathrm{pH}$} \\
\hline & & \multirow{2}{*}{$\begin{array}{l}\mathrm{pCO}_{2} \\
\mathrm{~mm} \mathrm{Hg}\end{array}$} & \multirow{2}{*}{$\begin{array}{l}\mathrm{HCO}_{3}{ }^{-}, \\
\text {mmol/liter }\end{array}$} & \multicolumn{3}{|c|}{$\mathrm{mEq} /$ liter } & \\
\hline & & & & $\mathrm{Na}^{+}$ & $\mathrm{K}^{+}$ & $\mathrm{Cl}^{-}$ & \\
\hline \multicolumn{8}{|l|}{ Before acidification } \\
\hline Mean & 7.49 & 32.6 & 25.0 & 144.8 & 4.12 & 108 & \\
\hline $\mathrm{SE}$ & 0.007 & 0.82 & 0.80 & 1.01 & 0.42 & 1.15 & \\
\hline \multicolumn{8}{|l|}{ After acidification } \\
\hline Mcan & 7.29 & 32.5 & 15.4 & 139.0 & 4.70 & 115 & 5.87 \\
\hline $\mathrm{SE}$ & 0.03 & 1.60 & 1.49 & 1.86 & 0.14 & 2.61 & 0.03 \\
\hline
\end{tabular}

Table 3. Values of plasma at threshold for bicarbonate

\begin{tabular}{|c|c|c|c|c|c|c|}
\hline & No. & $\mathrm{pH}$ & $\begin{array}{c}\mathrm{pCO}_{2}, \\
\mathrm{~mm} \mathrm{Hg}\end{array}$ & $\begin{array}{c}\mathrm{HCO}_{3}{ }^{-}, \\
\mathrm{mmol} / \mathrm{li}- \\
\text { ter }\end{array}$ & $\begin{array}{c}\mathrm{K}^{+}, \\
\mathrm{mEq} / \mathrm{li}- \\
\mathrm{ter}\end{array}$ & $\underset{\substack{\mathrm{Cl}^{-}, \mathrm{mEq} / \\
\text { liter }}}{ }$ \\
\hline \multirow[t]{9}{*}{ Fotus } & 71 & 7.27 & 50.3 & 22.7 & 4.6 & \\
\hline & 73 & 7.10 & 40.1 & 12.0 & 4.7 & \\
\hline & 74 & 7.13 & 49.2 & 15.5 & 4.5 & \\
\hline & 76 & 7.00 & 58.3 & 13.7 & 4.6 & \\
\hline & 80 & 7.28 & 31.7 & 14.4 & 4.9 & 106 \\
\hline & 82 & 7.31 & 47.8 & 23.5 & 5.1 & 101 \\
\hline & 83 & 7.32 & 40.0 & 20.0 & 5.6 & 106 \\
\hline & 84 & 7.33 & 39.9 & 20.5 & 4.9 & 103 \\
\hline & 85 & 7.26 & 38.6 & 17.1 & 5.4 & 104 \\
\hline $\bar{\chi}$ & & 7.22 & 43.98 & 17.71 & 4.92 & 104.0 \\
\hline $\mathrm{SE}$ & & 0.03 & 2.67 & 1.37 & 0.12 & 0.94 \\
\hline \multirow[t]{5}{*}{ Adult ewe } & 4 & 7.50 & 32.0 & 25.1 & 4.3 & 113 \\
\hline & 5 & 7.54 & 36.0 & 31.4 & 3.6 & 117 \\
\hline & 6 & 7.60 & 34.0 & 33.5 & 4.7 & 110 \\
\hline & 7 & 7.50 & 32.0 & 25.0 & 4.3 & 113 \\
\hline & 8 & 7.58 & 30.0 & 28.5 & 4.3 & 109 \\
\hline $\bar{\chi}$ & & 7.54 & 32.8 & 28.70 & 4.24 & 112.4 \\
\hline SE & & 0.02 & 1.07 & 1.68 & 0.17 & 1.39 \\
\hline$t$ & & 6,04 & 2.99 & 4.90 & 3.16 & 4.96 \\
\hline$P$ & & 0.001 & 0.01 & 0.001 & 0.005 & 0.001 \\
\hline
\end{tabular}

sion analysis shows a high correlation of fetal kidney weight with fetal age $(r=0.87)$ and a low partial correlation of age with plasma bicarbonate at threshold. Therefore, the plasma bicarbonate at threshold correlates primarily with fetal kidney weight and fetal age does not account for an independent source of variation.
EFFECTS OF EXTRACELLULAR VOLUME CONTRACTION ON RENAL REABSORPTION OF BICARBONATE IN FETAL SHEEP

The effect of extracellular volume contraction on bicarbonate reabsorption was evaluated in nine acute fetal preparations between 114 and 142 days of gestation.

Blood and urine values before and after contraction of the extracellular fluid volume in the fetus are summarized in Table 4. There is no significant difference in arterial blood values for $\mathrm{pH}, \mathrm{pCO}_{2}, \mathrm{PO}_{2}$, or in arterial plasma concentrations for bicarbonate, sodium, chloride, and osmolarity before and after extracellular volume contraction. There is a small but significant increase $(P<0.001)$ of $0.3 \mathrm{mEq} /$ liter in plasma concentration of potassium after volume contraction. There is no significant change in total protein and albumin concentration. However, there is an increase in hematocrit values from $45.8 \pm 1.8$ to 47.1 \pm 2.3 .

Urine values presented in Table 4 show that urine flow, GFR, and the amount of bicarbonate filtered are stable before and after peritoneal dialysis. However, there is a significant increase in reabsorbed bicarbonate $(P<0.01)$ and a significant decrease in urinary $\mathrm{pH}(P<0.025)$ and urinary excretion of bicarbonate $(P<0.001)$, sodium $(P<0.001)$, and chloride $(P<0.001)$ after contraction of the extracellular fluid volume in the fetus.

In five animals the dialysis fluid from the peritoneal cavity was collected at the end of the experiment and compared to the preexperimental solution of Dianeal for sodium, potassium, chloride, and osmolarity, as shown in Table 5. There was a significant decrease $(P<0.001)$ in the concentrations of $\mathrm{Na}^{+}, \mathrm{K}^{+}$and $\mathrm{Cl}^{-}$in the peritoneal dialysis fluid at the end of the dialysis period, indicating a transfer of water from the fetal extracellular space to the peritoneal cavity.

There was a decrease of $31.8 \%$ in the osmolarity and a $44.6 \%$ decrease in the glucose concentration in the peritoneal dialysis 
fluid at the end of the experimental period. 'The fall in osmolarity $(31.8 \%)$ was greater than the decrease in concentration of clectrolytes $(16.1 \%)$, suggesting that the glucose in dialysis fluid was passing from the peritoneal cavity to the fetal circulation. There was, however, no significant rise in arterial blood glucose in the fetus at the end of the dialysis period.

\section{IEFFICTS OF GLUCOSE ON BICARBONATI: REABSORPTION IN FETUS}

In order to verify whether the transfer of glucose from the dialy'sis fluid to the fetus could modify the response of the kidney to extracellular volume depletion, the glucose in the dialysis fluid was replaced by mannitol in three acute preparations. As shown in Table 6, there was no significant difference in GFR before and after peritoneal dialysis with mannitol. However, there was a significant decrease in excreted bicarbonate $(P<0.025)$ and sodium $(P<0.025)$ and a significant increment $(P<0.1)$ in reabsorbed bicarbonate. There was also a decrease (not significant) in urinary pll. These results paralleled those when Diancal containing glucose was used as peritoneal dialysis fluid (Table $4)$.

In a second series of experiments using two chronic fetal

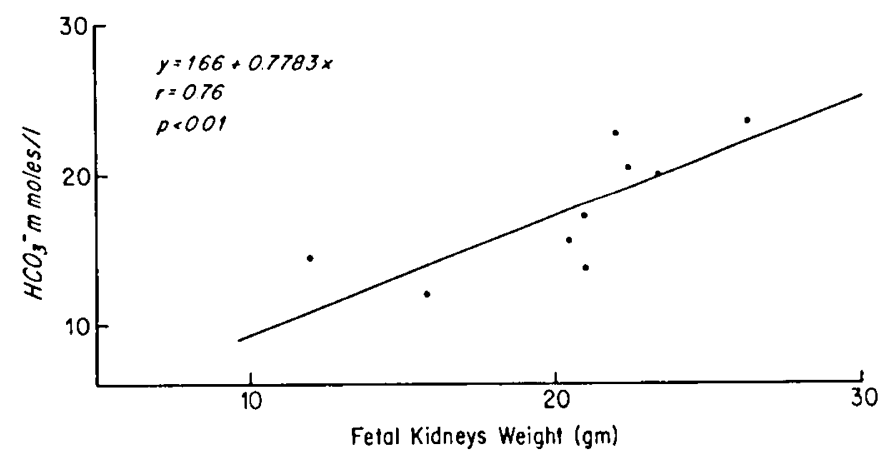

Fig. 1. Relaionship between fetal kidney weight and plasma bicarbonate at threshold. models, the arterial plasma glacose concentration was increased over $200 \mathrm{mg} / 100 \mathrm{ml}$ without contracting the fetal extracellular volume. During this experiment the amount of bicarbonate reabsorbed decreased by a mean of $1.2 \pm 0.08 \mu \mathrm{Ec} / \mathrm{ml}$ GFR when the GFR and arterial blood values remained stable.

\section{DISCUSSION}

Since the renal secretory capacity of hydrogen ions involves the reabsorption of bicarbonate and since presently available data on the fetus $(30,41)$ deal only with the excretion of ammonium and titrable acid to explain the metabolic acidosis in the fetus, the present study was designed to investigate the contribution of bicarbonate reabsorption to acid secretion during fetal life.

In the first part of this study it is demonstrated that the values of plasma bicarbonate at threshold for renal bicarbonate excretion are lower in the fetal lamb than in nonpregnant adult ewes. It is also shown that the level of plasma bicarbonate at threshold increases significantly with fetal kidney weight $(P<0.01)$.

In the present study, the bicarbonate threshold was determined in the adult nompregnant ewes after they had received 3

Table 5. Analysis of dialysis fluid before and after peritoneal dialysis in five feruse's

\begin{tabular}{|c|c|c|c|c|c|}
\hline & \multicolumn{3}{|c|}{ ml:q/liter } & \multirow{2}{*}{$\begin{array}{l}\text { Osmolar- } \\
\text { ity, } \\
\mathrm{mOsm} / \mathrm{kg} \\
\mathrm{H}_{2} \mathrm{O}\end{array}$} & \multirow{2}{*}{$\begin{array}{l}\text { Glucose, } \\
\mathrm{g} / 100 \mathrm{ml}\end{array}$} \\
\hline & $\mathrm{Na}$ & K & (1) & & \\
\hline \multicolumn{6}{|c|}{$\begin{array}{l}\text { Before } \\
\qquad(n=5)\end{array}$} \\
\hline $\bar{\chi}$ & 138.8 & 4.32 & 103.4 & 497.2 & 3.96 \\
\hline $\mathrm{SE}$ & 0.37 & 0.13 & 0.24 & 1.06 & 0.01 \\
\hline \multicolumn{6}{|c|}{$\begin{array}{l}\text { After } \\
\qquad(n=5)\end{array}$} \\
\hline $\bar{\chi}$ & 117.0 & 3.32 & 86.4 & 3.39 .2 & 2.19 \\
\hline SE & 1.54 & 0.13 & 1.56 & 18.7 & 0.09 \\
\hline$P$ & $<0.001$ & $<0.001$ & $<0.001$ & $<0.001$ & $<0.001$ \\
\hline
\end{tabular}

Table 4. Summary of blood and urine values before and after peritoneal dialysis in nine fetuses'

\begin{tabular}{|c|c|c|c|c|c|}
\hline & \multicolumn{2}{|c|}{ Before } & \multicolumn{2}{|c|}{ After } & \multirow[b]{2}{*}{$P$} \\
\hline & $\bar{\chi}$ & SE: & $\bar{x}$ & SE & \\
\hline \multicolumn{6}{|l|}{ Blood } \\
\hline $\mathrm{pH}$ & 7.358 & 0.007 & 7.352 & 0.01 & N.S. \\
\hline $\mathrm{pCO}_{2}, \mathrm{~mm} \mathrm{Hg}$ & +1.1 & 0.84 & 41.4 & 0.87 & N.S. \\
\hline $\mathrm{pO}_{2}, \mathrm{~mm} \mathrm{Hg}$ & 22.3 & 1.82 & 22.5 & 1.49 & N.S. \\
\hline $\mathrm{HCO}_{3}{ }^{-}, \mathrm{mmol} / \mathrm{liter}$ & 22.7 & 0.37 & 22.7 & 0.58 & N.S. \\
\hline $\mathrm{Na}^{+}, \mathrm{mEq} /$ liter & 136.5 & 1.15 & 1.36 .2 & 1.05 & N.S. \\
\hline $\mathrm{K}^{+}, \mathrm{mEq} /$ liter & 4.8 & 0.14 & 4.5 & 0.12 & $<0.001$ \\
\hline $\mathrm{Cl}^{-}, \mathrm{mEq} /$ liter & 99.7 & 0.84 & 99.4 & 0.97 & N.S. \\
\hline Total protein, $\mathrm{g} / 100 \mathrm{ml}$ & 3.67 & 0.21 & 3.61 & 0.15 & N.S. \\
\hline Albumin, $\mathrm{g} / 100 \mathrm{ml}$ & 1.99 & 0.11 & 1.92 & 0.09 & N.S. \\
\hline Osmolarity, $\mathrm{mOsm} / \mathrm{kg}$ & 283 & 2.8 & 285 & 3.3 & N.S. \\
\hline Hematocrit & 45.8 & 1.8 & 47.1 & 2.3 & N.S. \\
\hline \multicolumn{6}{|l|}{ Urine } \\
\hline Flow, $\mathrm{ml} / \mathrm{min}$ & 0.47 & 0.10 & 0.37 & 0.12 & N.S. \\
\hline $\mathrm{GFR}, \mathrm{ml} / \mathrm{min}$ & 0.88 & 0.10 & 0.82 & 0.09 & N.S. \\
\hline $\mathrm{pH}$ & 7.18 & 0.12 & 6.91 & 0.19 & $<0.025$ \\
\hline $\mathrm{F}_{\mathrm{H}\left(\mathrm{O}_{3}-\right.}, \mu \mathrm{Eq} / \mathrm{ml} \mathrm{GFR}$ & 22.70 & (). .37 & 22.70 & 0.58 & N.S. \\
\hline $\mathrm{R}_{\mathrm{HH}^{\prime} \omega_{3}-}, \mu \mathrm{Eq} / \mathrm{ml} \mathrm{GFR}$ & 19.10 & 1.14 & 20.60 & 0.90 & $<0.01$ \\
\hline $\mathrm{E}_{\mathrm{HCO} \mathrm{e}_{3}-}, \mu \mathrm{Eq}_{\mathrm{q} / \mathrm{ml} \mathrm{GFR}}$ & 3.61 & 0.85 & 2.04 & 0.80 & $<0.001$ \\
\hline $\mathrm{E}_{\mathrm{x}_{\mathrm{it}}+}, \mu \mathrm{Eq} / \mathrm{ml} \mathrm{GFR}$ & 14.70 & 3.70 & 8.72 & 2.95 & $<0.001$ \\
\hline $\mathrm{C}_{\mathrm{Nit}} \cdot / \mathrm{C}_{\mathrm{llwh}} \times 100$ & 10.70 & 2.68 & 6.30 & 2.10 & $<0.001$ \\
\hline $\mathrm{E}_{\left(\mathrm{l}^{-}\right.}, \mu \mathrm{Eq} / \mathrm{ml} \mathrm{GFR}$ & 10.53 & 2.84 & 5.97 & 2.19 & $<0.001$ \\
\hline $\mathrm{C}_{(\mathrm{g})} / \mathrm{C}_{\mathrm{luth}} \times 100$ & 10.40 & 2.70 & 6.00 & 2.20 & $<0.001$ \\
\hline
\end{tabular}

1 GFR: glomerular filtration rate; F: filtered; $R$ : reabsorbed; E: excreted; $C / C_{\text {luth }} \times 100$ : percentage of filtered electrolytes excreted. 
Table 6. Effect of peritoneal dialysis with mannitol in three fetuses ${ }^{1}$

\begin{tabular}{|c|c|c|c|c|c|c|c|c|c|c|c|}
\hline & \multicolumn{6}{|c|}{ Plasma } & \multicolumn{5}{|c|}{ Urine } \\
\hline & \multirow[b]{2}{*}{$\mathrm{pH}$} & \multirow[b]{2}{*}{$\begin{array}{l}\mathrm{pCO}_{2} \\
\mathrm{~mm} \mathrm{Hg}\end{array}$} & \multirow[b]{2}{*}{$\begin{array}{c}\mathrm{pO}_{2}, \\
\mathrm{~mm} \mathrm{Hg}\end{array}$} & \multirow{2}{*}{$\begin{array}{c}\mathrm{HCO}_{3}{ }^{-}, \\
\text {mmol/ } \\
\text { liter }\end{array}$} & \multirow[b]{2}{*}{$\begin{array}{l}\mathrm{Na}^{+}, \\
\mathrm{mEq} / \mathrm{liter}\end{array}$} & \multirow{2}{*}{$\begin{array}{c}\text { Osmolar- } \\
\text { ity, } \\
\text { mOsm/ } \\
\text { kg }\end{array}$} & \multirow[b]{2}{*}{$\begin{array}{l}\text { GFR, } \\
\mathrm{ml} / \mathrm{min}\end{array}$} & \multicolumn{4}{|c|}{$\mu \mathrm{Eq} / \mathrm{min} / \mathrm{ml} \mathrm{GFR}$} \\
\hline & & & & & & & & $\mathrm{pH}$ & $\mathrm{R}_{\mathrm{HCO}_{3}-}$ & $\mathrm{E}_{\mathrm{HCO}_{3}^{-}}$ & $\mathrm{E}_{\mathrm{Na}^{+}}$ \\
\hline \multicolumn{12}{|c|}{$\begin{array}{l}\text { Before } \\
\qquad(n=3)\end{array}$} \\
\hline $\bar{\chi}$ & 7.31 & 39.4 & 30.01 & 19.81 & 133.6 & 283.4 & 2.44 & 7.21 & 15.48 & 4.16 & 16.15 \\
\hline SE & 0.02 & 3.68 & 3.68 & 1.43 & 1.15 & 2.81 & 0.67 & 0.22 & 3.01 & 1.71 & 4.57 \\
\hline \multicolumn{12}{|c|}{$\begin{array}{l}\text { After } \\
\qquad(n=3)\end{array}$} \\
\hline $\bar{x}$ & 7.30 & 40.3 & 30.06 & 19.44 & 132.7 & 285.5 & 2.69 & 7.10 & 16.93 & 2.54 & 10.56 \\
\hline SE & 0.04 & 3.12 & 3.12 & 1.23 & 1.07 & 0.85 & 0.66 & 0.31 & 2.25 & 1.22 & 2.95 \\
\hline$P$ & N.S. & N.S. & N.S. & N.S. & N.S. & $<0.1$ & N.S. & N.S. & $<0.1$ & $<0.025$ & $<0.025$ \\
\hline
\end{tabular}

' GFR: glomerular filtration rate; R: reabsorbed; E: excreted.

days of ammonium chloride. Then, it could have been possible that they were volume contracted. However, during the period of ammonium chloride injection the adult sheep were not restricted in water and their weight difference before and after ingestion of ammonium chloride was not statistically different. Therefore, it seems very unlikely that the difference in the bicarbonate threshold values between the fetuses and the adult nonpregnant ewes was secondary to phenomena other than developmental.

Anatomic immaturity of the nephron may be a factor that explains the low threshold in the fetus. Previous studies in newborn animals indicated that the increase in kidney weight with age reflects the predominant growth of the proximal tubule $(9,21)$ and suggested that early morphologic glomerular preponderance is paralleled by functional glomerular preponderance. Recently, however, Horster and Valtin (15), Spitzer and Brandis (33), and Solomon (32), using micropuncture studies, showed in different newborn animal models that proportionality between filtration and reabsorption of sodium and water in superficial proximal tubules is maintained through development, and that functional glomerulotubular balance is present throughout the entire period of renal maturation. Micropuncture studies, however, are not available in the fetus for comparison. Thus it is not possible, at this time, to state whether or not the low threshold for bicarbonate in the lamb fetuses represents functional glomerulotubular imbalance.

Other factors such as plasma $\mathrm{pCO}_{2}$ tension, plasma chloride concentration, body potassium stores, carbonic anhydrase activity, and stimuli affecting sodium reabsorption may also play a role in explaining the low renal threshold for bicarbonate found in the fetuses. In the present study the plasma bicarbonate at threshold is lower in the fetuses than in adult ewes despite significantly higher $\mathrm{pCO}_{2}$ values in the fetus $(P<0.01)$. It is well known that an increase in arterial $\mathrm{pCO}_{2}$ in vivo will increase bicarbonate reabsorption (23). Therefore, the higher $\mathrm{pCO}_{2}$ values in the fetuses would tend to increase bicarbonate reabsorption.

The presence of a lower chloride concentration in the fetuses versus the adult ewes $(P<0.001)$ has probably no direct effect on the low fetal renal threshold for bicarbonate. The mechanism by which chloride influences renal bicarbonate reabsorption seems to be indirect and related to changes in extracellular volume $(4,28)$. It is shown that when chloride is selectively depleted, it is not the low plasma chloride concentration but rather the contracted extracellular fluid volume that is most important in maintaining the relatively high rate of hydrogen secretion (4). Kurtzman (17) has also shown that expansion of effective extracellular volume results in a decreased chloride and bicarbonate reabsorption.

It is thus possible that this low fetal plasma chloride concentration may be secondary to the high extracellular fluid volume found normally in the fetus $(10,42)$ and may parallel the low fetal renal threshold for bicarbonate.

Plasma potassium concentration was found to be higher in the fetuses than in adult ewes $(P<0.005)$. It has long been known that an increase in plasma potassium concentration will reduce bicarbonate reabsorption by limiting intracellular hydrogen ions available to the exchange mechanism (22). However, the fetuses with high plasma potassium concentrations also have the highest values for plasma bicarbonate at threshold. Therefore, it seems unlikely that the difference in renal bicarbonate threshold values between fetal and adult animals is related to the high fetal plasma potassium concentration.

The presence of an active carbonic anhydrase enzyme has been demonstrated in the fetal lamb during the last half of gestation (26). It has been shown in acute (31) and chronic (25) fetal preparations that the renal response to administration of a carbonic anhydrase inhibitor, acetazolamide, is similar to that observed in the adult sheep. Thus, the low threshold for renal bicarbonate reabsorption found in the fetus is probably not secondary to a lack of fetal renal carbonic anhydrase activity. However, enzyme kinetic studies are needed to clearly demonstrate that point.

The stimuli affecting tubular sodium reabsorption will also modify reabsorption of filtered bicarbonate (36). Kurtzman (17) has shown previously in adult dogs that expansion of extracellular volume, known to depress sodium reabsorption (35), decreased bicarbonate reabsorption. Moore (19) demonstrated that the decreased threshold for bicarbonate found in puppies 1 4 weeks of age can be markedly increased under the stimulus of extracellular volume concentration.

In the second part of this study a mild contraction of extracellular fluid volume, using peritoneal dialysis, was induced in the fetuses to determine whether factors that stimulate sodium reabsorption in adult and newborn animals $(17,19)$ have an effect upon fetal bicarbonate reabsorption. These experiments show that, parallel to the contraction of fetal extracellular volume, there is a significant increase in bicarbonate reabsorption $(P<$ $0.01)$ and a significant decrease in urine $\mathrm{pH}(P<0.025)$, excreted bicarbonate $(P<0.001)$, sodium $(P<0.001)$, and chloride $(P<0.001)$.

It is then possible that the state of high extracellular fluid volume found normally in the fetus is a major determinant of bicarbonate reabsorption by the fetal kidney. The present data shows that during fetal peritoneal dialysis water is removed from the fetus and added to the peritoneal cavity. It is also demonstrated that during this process there is an increase in bicarbonate and electrolyte reabsorption in the fetus. However, even if the present data suggest a parallelism between a mild contraction of extracellular volume and bicarbonate reabsorption during fetal life, this study does not permit evaluation of the exact amount of effective extracellular fluid volume removed and the 
effect of this procedure on placental exchange of solute and water. Furthermore, it is possible that physical factors others than the contraction of extracellular volume alone may have influenced the present findings.

Oncotic pressure within the postglomerular microcirculation has been shown to influence proximal reabsorption of electrolytes in adult experimental animals (34) and is regulated by peripheral plasma protein concentration and filtration fraction (6). In the present study, there is no modification in peripheral plasma protein concentration; however, filtration fraction was not determined. It is possible that the extracellular volume depletion may have influenced the filtration fraction in the direction of increasing bicarbonate and electrolyte reabsorption. The small rise in hematocrit found at the end of the dialysis period, even if not significant, may also have influenced the tubular function by changing the viscosity of the blood and the flow and pressure in peritubular capillaries $(3,16)$. It is then conceivable that factors other than the contraction of extracellular volume might have influenced the increase in bicarbonate reabsorption during the fetal peritoneal dialysis.

It is also possible that the increase in fractional bicarbonate and electrolyte reabsorption by the fetal kidney may be related to an increase in aldosterone secretion during the period of fetal peritoneal dialysis. However, the present study was not designed to investigate this aspect.

The use of an acute experimental preparation may also have modified the response to volume depletion. Spinal anesthesia, as used in the present study, is not known to have any effect on the metabolic and cardiovascular functions of the fetus (2); on the other hand, it is known that operative and anesthetic stresses might affect kidney function, especially the tubular reabsorption of water (12). However, since in the present study every fetus is used as its own control, it is clear that the results obtained after peritoneal dialysis are not artifacts.

Since glucose increases bicarbonate reabsorption in man (11) and in dogs (37), it was important to determine whether the passage of glucose from the dialysis fluid to the fetus during the process of extracellular volume contraction could have influenced the renal bicarbonate reabsorption in the fetus. It is improbable since it was not possible to demonstrate a significant increase in fetal plasma glucose at the end of the dialysis period. It is possible, however, that glucose passing from the peritoneal fluid to the fetus was cleared rapidly by the placenta (1) or used by the fetus (39). Furthermore, when the fetal plasma glucose was increased above $200 \mathrm{mg} / 100 \mathrm{ml}$ in the chronic preparation there was no effect on renal bicarbonate reabsorption. Finally, using three acute fetal preparations, mannitol was substituted for glucose in the dialysis solution in order to produce extracellular volume contraction. The results of these studies (Table 6) indicate that the effects of extracellular volume contraction on bicarbonate reabsorption paralleled the results obtained when glucose was used as osmotic agent in the dialysis fluid (Table 4). Thus it is clear that the increase in bicarbonate reabsorption and the decrease in fractional excretion of sodium are not secondary to an effect of glucose on fetal bicarbonate reabsorption.

In summary, it has been demonstrated that the fetal threshold for renal bicarbonate excretion is lower than in the adult. This finding, added to the limited ability of the fetal kidney to excrete titrable acid and ammonia $(30,41)$, explains more completely why the fetal kidney is limited in its ability to establish adult-type gradient of $\mathrm{pH}$ between blood and urine. It has also been suggested that the fetal kidney is able to increase bicarbonate and sodium reabsorption under the stimulus of the contraction of the fetal extracellular fluid volume. It has been shown previously in adult animals $(17,20)$ and newborn puppies (19) that extracellular volume changes modify bicarbonate reabsorption. However, factors such as the oncotic pressure in the fetal peritubular capillary circulation, the influence of distribution in intrarenal blood flow during fetal life, the activity of the renin-angiotensinaldosterone system, and the effect of $\alpha$ and $\beta$ adrenergic stimulation in the fetus may have influenced bicarbonate reabsorption during the period of peritoneal dialysis and need to be evaluated. Finally, it is also shown that glucose has no effect on bicarbonate and sodium reabsorption during fetal life.

\section{CONCLUSION}

The ability of the fetal kidney to excrete fixed acids and to establish an adult gradient of $\mathrm{pH}$ between blood and urine has been investigated previously $(30,41)$. In order to examine the capacity of fetal kidney to reabsorb bicarbonate, in the first part of the study it was shown that the values of plasma bicarbonate at threshold for renal bicarbonate excretion are lower in the fetal lambs than in adult nonpregnant ewes. It was also shown that the level of plasma bicarbonate at threshold increases significantly with fetal kidney weight $(P<0.01)$ and with fetal age $(P<$ 0.05 ). In the second part of the study it was possible to show that contraction of fetal extracellular volume using peritoneal dialysis significantly increases bicarbonate reabsorption $(P<0.01)$ and significantly decreases urine pH $(P<0.025)$, excreted bicarbonate $(P<0.001)$, sodium $(P<0.001)$, and chloride $(P<$ $0.001)$. Finally, it was demonstrated that the increment in bicarbonate reabsorption and the reduction in fractional excretion of sodium after peritoneal dialysis were not secondary to an effect of glucose on fetal bicarbonate reabsorption. The findings of this study suggest that the fetal kidney, under the stimulus of volume depletion, is not limited in its capacity to reabsorb sodium and bicarbonate.

\section{REFERENCES AND NOTES}

1. Alexander, D. P., Huggett, A. G.. Nixon, D. A., and Widdas, W. F.: The placental transfer of sugars in the sheep: The influence of concentration gradient upon the rates of hexose formation as shown in umbilical perfusion of the placenta. J. Physiol., 129: 367 (1955).

2. Assali, N. S., Brinkman, C. R., III, and Nuwayhid, B.: Comparison of maternal and fetal cardiovascular functions in acute and chronic experiments in the sheep. Amer. J. Obstet. Gynecol., 120: 411 (1974).

3. Clapp, J. R.: Factors affecting proximal sodium reabsorption in response to acute volume contraction. Clin. Res., 18: 61 (1970).

4. Cohen, J. J.: Correction of metabolic acidosis by the kidney after isometric expansion of extracellular fluid. J. Clin. Invest., 47: 1181 (1968).

5. Dawes, G. S., Fox, H. E., Leduc, B. M., Liggins, G. C., and Richards, R. T.: Respiratory movements and rapid eye movement sleep in the foetal lamb. J. Physiol. (London), 220: 119 (1972).

6. Earley, L. A., and Schrier, R. W.: Intrarenal control of sodium excretion by hemodynamic and physical factors. In: J. Orloff and R. W. Berliner: Handbook of Physiology, Section 8: Renal physiology, p, 740 (American Physiological Society, Washington, D.C., 1973).

7. Edelmann, C. M., Jr., Rodriguez Soriano, S., Boichis, H., Gruskin, A. B., and Acosta, M. I.: Renal bicarbonate reabsorption and hydrogen ion excretion in normal infants. J. Clin. Invest., 46: 1309 (1967).

8. Failing, J. F., Jr., Buckley, M. W., and Zak, B.: A study on an ultramicro and automated procedure for serum proteins. Amer. J. Med. Tech., 27: 177 (1961).

9. Fetterman, G. H., Shuplock, N. A., Philipp, F. S., and Gregg, H. S.: The growth and maturation of human glomeruli and proximal convolutions from term to adulthood. Pediatrics, 35: 601 (1965)

10. Friis-Hansen, B.: Body water compartments in children: Changes during growth and related changes in body composition. Pediatrics, 28: 169 (1961).

11. Goodyear, A. V. N., Welt, L. G., Darrach, J. H., Abele, W. A., and Meroney, W. H.: Effect of glucose diuresis on renal excretion of bicarbonate. Proc. Soc. Exp. Biol. Med., 86: 19 (1954).

12. Gresham, E. I., Rankin, J. K. G., Makowski, E. L., Meschia, G., and Battaglia, F. C.: An evaluation of fetal renal function in a chronic sheep preparation. J. Clin. Invest., 51: 149 (1972).

13. Hales, J. R. S., and Webster, M. E. D.: Respiratory function during thermal tachypnoca in sheep. J. Physiol. (London), 190: 241 (1967).

14. Hastings, A. B., and Sendroy, J.: The effect of variation in ionic strength on the apparent first and second dissociation constants of carbonic acid. J. Biol Chem., 65: 445 (1925)

15. Horster, M., Kemler, B. J., and Valtin, H.: Intracortical distribution of number and volume of glomeruli during postnatal maturation in the dog. $\mathrm{J}$. Clin. Invest., 50: 796 (1971).

16. Knox, F. G., Howards, S. S., Wright, F. S., Davis, B. B., and Berliner, R. $\mathrm{W}$.: Effect of dilution and expansion of blood volume on proximal sodium reabsorption. Amer. J. Physiol., 215: 1041 (1968).

17. Kurtzman, N. A.: Regulation of renal bicarbonate reabsorption by extracellular volume. J. Clin. Invest., 49: 586, (1970).

18. Moore, E. S., de Hannoy, C. W., Paton, J. B., and Ocampo, M.: Effect of $\mathrm{Na}_{2} \mathrm{SO}_{4}$ on urinary acidification in the fetal lamb. Amer. J. Physiol., 223: $167(1972)$. 
19. Moore, E. S., Fine, B. P., Satrosook, S. S., Vergel, Z. M., and Edelmann, C. M., Jr.: Renal reabsorption of bicarbonate in puppies: Effect of intracellular volume contraction on the renal threshold for bicarbonate. Pediat. Res., 6: 859 (1972).

20. Parkenson, M. L., Lubowitz, H., White, R. S., and Bricker, N. S.: On the influence of extracellular fluid volume expansion on bicarbonate reabsorption in the rat. J. Clin. Invest., 48: 1754 (1969).

21. Potter, D. Jarrah, A., Sakai, T., Harrah, J., and Holliday, M. A.: Character of function and size in kidney during normal growth of rats. Pediat. Res., 3: 51 (1969).

22. Rector, F. C., Jr., Bloomer, H. A., and Seldin, D. W.: Effects of K deficiency on reabsorption of bicarbonate in the proximal tubule of the rat. J. Clin. Invest., 43: $1976(1964)$

23. Rector, F. C., Jr., Seldin, D. W., Roberts, A. D., Jr., and Smith, J. S.: The role of plasma $\mathrm{CO}_{2}$ tension and carbonic anhydrase activity in the renal reabsorption of bicarbonate. J. Clin. Invest., 39: 1706 (1960)

24. Rohillard, J. E. Kulvinskas, C. Sessions, C., Burmeister, L., and Smith, F. G.. Jr.: Maturational changes in the fetal glomerular filtration rate. Amer. J. Obstet. Gynecol., 122: 601 (1975).

25. Robillard, J. E., Sessions, C., Kennedy, R., Burmeister, L., and Smith, T. G., Jr.: Renal carbonic anhydrase activity in the chronic fetal lamb. (In preparation.)

26. Robillard, J. E., Smith, F. G., Jr., Kulvinskas, C., and Braden, E.: Carbonic anhydrase function in the fetal kidney [Abstr.]. Pediat. Res., 7: 188 (1973).

27. Saloman, L. L., and Johnson, J. E.: Enzymatic microdetermination of glucose in blood and urine. Anal. Chem., 31:453 (1959)

28. Seldin, D. W., and Rector, F. C., Jr.: The generation and maintenance of metabolic acidosis. Kidney Intern., I: 306 (1972)

29. Siggaard Andersen, O., and Engel, K.: A new acid-base nomogram method for the calculation of the relevant blood acid-base data. Scand. J. Clin. Invest., 12: $177(1960)$.

30. Smith, F. G., Jr., and Schwartz, A.: Response of the intact lamb fetus to acidosis Amer. J. Obstet. Gynecol., 106: 52 (1970).

31. Smith, F. G., Jr., Tinglof, B., and Adams, F. H.: Renal phosphate clearance and bicarbonate excretion in the fetal lamb [Abstr.]. J. Pediat., 67: 955 (1965).

32. Solomon, S.: Absolute rates of sodium and potassium reabsorption by proximal tubule of immature rats. Biol. Neonate, 25: 340 (1974).

33. Spitzer, A., and Brandis, M.: Functional and morphologic maturation of the superficial nephrons. J. Clin. Invest., 53: 279 (1974).

34. Spitzer, A., and Windhager, E. E.: Effect of peritubular oncotic pressure changes on proximal tubular fluid reabsorption. Amer. J. Physiol., 218: $1188(1970)$.

35. Stein, J. H., and Reineck, H. J.: Effect of alterations in extracellular fluid volume on segmental sodium transport. Physiol. Rev. 55: 127 (1975).

36. Steinmetz, P. R.: Cellular mechanisms of urinary acidification. Physiol. Rev., 54: $890(1974)$.

37. Suki, W. N., Hebert, C. S., Stincbaugh, B. J., Martinez-Maldonado, M., and Eknogan, G.: Effects of glucose on bicarbonate reabsorption in the dog kidney. J. Clin. Invest., 54: 1 (1974)

38. Svenningsen, N. W.: Renal acid-base titration studies in infants with and without metabolic acidosis in the postneonatal period. Pediat. Res., 8: 659 (1974).

39. Tsoulos, N. G.: Comparison of glucose, fructose and $\mathrm{O}_{2}$ uptakes by fetuses of fed and starved ewes. Amer. J. Physiol.,221: 234 (1971)

40. Van Slyke, D. D., and Neill, J. M.: The determination of gases in blood and other solutions by vacuum extraction and manometric measurement. J. Biol. Chem., 61: 523 (1924).

41. Vaughn, D. Kirschbaum, T. H. Bersentes, T., Dilts, P. V., Jr., and Assali, N. S.: Fetal and neonatal response to acid loading in the sheep. J. Appt. Physiol., 24: 135 (1968).

42. Widdowson, E. M.: Growth and composition of the fetus and newborn. In: N. S. Assali: Biology of Gestation, p. 1 (Academic Press, New York, 1968).

43. Xylocaine, Astra Pharmaceutical Products, Inc., Worchester, Mass.

44. Harvard Apparatus, Millis, Mass.

45. Baxter Laboratories.

46. Glofil, Abbott Laboratories, North Chicago, Ill.

47. Radiometer, London Co.. Cleveland, Ohio.

48. Instrument Laboratory, Lexington, Mass.

49. Buchler Instruments, Inc., Fort Lee, N. J.

50. Advanced Instruments, Inc., Needham Ileights, Mass.

51. Beckman Instruments, Inc., Palo Alto, Calif.

52. A preliminary report of these findings was presented at the 1975 Annual Meeting of the American Pediatric Society - The Society for Pediatric Research (Pediat Res., 9: 378 (1975)

53. This research was supported by Research Grant No HD 08953 from the National Institute of Child Health and Human Development and Research Grant MA-5652 from the Canadian Medical Research Council.

54. Requests for reprints should be addressed to: J. E. Robillard, M.D., Department of Pediatrics, Division of Nephrology, University of Iowa llospital and Clinics, Iowa City, Iowa, 52240 (USA).

55. Received for publication February 18, 1976.

56. Accepted for publication September 30, 1976.

\title{
Cyclic Nucleotide Phosphodiesterase Activities of the Fetal and Mature Human Cerebral Cortex
}

\author{
ELLEN S. KANG ${ }^{(52)}$ \\ WITH THE TECHNICAL ASSISTANCE OF DANIEL L. ELLSWORTH \\ Department of Biochemistry, St. Jude Children's Research Hospital, and the Department of Pediatrics, University of \\ Tennessee Center for the Healti Sciences, Memphis, Tennessee, USA
}

\section{Summary}

Phosphodiesterase activities were examined in the supernatant and pellet fractions of a $30,000 \times g$ preparation of brain tissues from human fetuses and young adults. Differences in total activity and distribution of the high and low $K_{m}$ activity enzymes for adenosine and guanosine $3^{\prime}, 5^{\prime}$-monophosphate (cyclic AMP and cyclic GMP, respectively) were found. The mature cortex had 10 times more activity than the fetal brain for cyclic AMP hydrolysis and 15-20 times more activity for cyclic GMP hydrolysis. In the fetus, more activity for both nucleotides at both high and low concentrations is associated with the supernatant fraction. With maturity, a shift in localization of high $\mathrm{K}_{\mathrm{m}}$ activity for cyclic GMP and low $K_{m}$ activities for both nucleotides to the particulate fraction is observed.

Michaelis constants for both mature and immature brains are similar. The $K_{m}$ values for cyclic $A M P$ are $10^{-4}$ and $10^{-5} \mathrm{M}$ and $10^{-4}$ and $10^{-6} M$ for cyclic GMP. The $V_{\max }$ values differed by a factor of 10 between the high $K_{m}$ and the low $K_{m}$ forms for each substrate. 